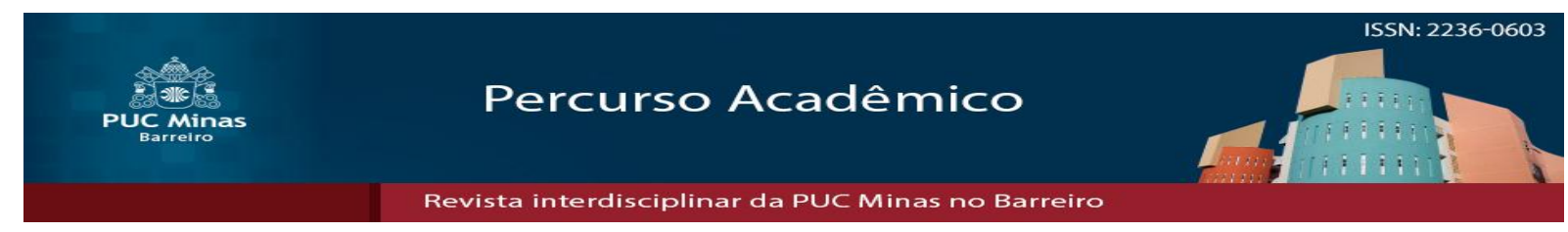

\title{
Como criar o caos social: mídia e políticas sobre drogas
}

\section{How to create social chaos: media and drug policies}

\author{
Carolina dos Reis ${ }^{1}$ \\ Daniel Dall'Igna Ecker ${ }^{2}$ \\ Vera Lucia Pasini ${ }^{3}$ \\ Samantha Torres ${ }^{4}$
}

\begin{abstract}
Resumo
O presente artigo objetiva apresentar uma análise de publicações veiculadas na mídia gaúcha sobre álcool e outras drogas. Para isso, foram selecionadas publicações de maio a junho de 2009 de três jornais impressos de grande circulação pelo estado do Rio Grande do Sul, sendo eles: Correio do Povo, Jornal do Comércio e Zero Hora. Em um primeiro momento, visibilizam-se os contextos em que emergem as entrevistas a partir dos gêneros jornalísticos, sua distribuição, localização, autoria, uso de imagens e fontes citadas. Em seguida, são apresentados os conteúdos das reportagens que foram organizados em 5 (cinco) principais categorias, são elas: 1) Drogas: "entidades" de vida própria; 2) Usuários: perigosos; 3) Quem fala na mídia: os "especialistas"; 4) Campos de saber; 5) Soluções apontadas: higienismo e repressão. Ao final, apontam-se possíveis reflexões sobre a importância do diálogo entre Psicologia e Mídia na busca por instituir práticas de cuidado integral aos usuários de drogas.
\end{abstract}

Palavras-chave: Políticas de drogas. Mídia. Processos de Subjetivação.

\begin{abstract}
This article aims to presents an analysis of the publications that circulated on the media of the state of Rio Grande do Sul about alcohol and other drugs. To this, the publications selected for review were from May to June of 2009, from three newspapers with a large circulation on Rio Grande do Sul, which are: Correio do Povo, Jornal do Comércio e Zero Hora. In the first moment, we visibilize the contexts in which emerge the journalistic's interviews, starting from their genres, distribution, location, authorship, use of images and sources cited. Then, the contents of the newspapers reports are presented, organized into 5 (five) major categories, they are: 1) Drugs: "entities" of own life; 2) Users: hazardous; 3) Who speaks in the media: the "experts "; 4) Fields of knowing; 5) Solutions identified: hygienism and repression. In the end, we pointed out possible reflections on the importance of dialogue between Psychology and Media in the search for instituting practices of integral health care of drug users.
\end{abstract}

Keywords: Drug policies. Media. Processes of Subjectivity.

Artigo recebido em 18 de Agosto de 2017 e aprovado em 23 de Maio de 2018

${ }^{1}$ Professora no Departamento de Psicologia Social e Institucional da Universidade Federal do Rio Grande do Sul, integrante do Núcleo de Estudos em Políticas e Tecnologias Contemporâneas de Subjetivação (E-politics) e do Núcleo de Estudos Sobre Drogas (NUCED). Atuou como Assessora Técnica de Políticas Públicas no CREPOP - Centro de Referências Técnicas em Psicologia e Políticas Públicas - do Conselho Regional de Psicologia do Rio Grande do Sul (CRPRS) 2010-2014. E-mail: carolinadosreis@ gmail.com.

${ }^{2}$ Psicólogo, Mestre em Psicologia Social e Institucional pelo Programa de Pós-Graduação em Psicologia Social e Institucional (PPGPSI) da Universidade Federal do Rio Grande do Sul (UFRGS). Doutorando (Bolsista CAPES) junto ao Grupo de Pesquisa: Travessias: Narrações da Diferença - Clínica, Pesquisa e Intervenção do PPSPSI da UFRGS. Atuou como Estagiário de psicologia no CREPOP - Centro de Referências Técnicas em Psicologia e Políticas Públicas - do Conselho Regional de Psicologia do Rio Grande do Sul (CRPRS) 2013. E-mail: daniel.ecker@hotmail.com.

${ }^{3}$ Professora Dr ${ }^{\mathrm{a}}$ Adjunta do Curso de Psicologia da Universidade Federal do Rio Grande do Sul (UFRGS). Atuou como Conselheira de Referência no CREPOP - Centro de Referências Técnicas em Psicologia e Políticas Públicas - do Conselho Regional de Psicologia do Rio Grande do Sul (CRPRS) 2010-2012. E-mail: verapasini@gmail.com.

${ }^{4}$ Psicóloga, Mestra em Psicologia Social e Institucional pelo Programa de Pós-Graduação em Psicologia Social e Institucional (PPGPSI) da Universidade Federal do Rio Grande do Sul (UFRGS/2016). Integra, desde 2012, o Centro de Referência Rede Multicêntrica (UFRGS) no colegiado gestor e como docente. Atuou como Estagiária de psicologia no CREPOP - Centro de Referências Técnicas em Psicologia e Políticas Públicas - do Conselho Regional de Psicologia do Rio Grande do Sul (CRPRS) 2012. E-mail: torres.samantha@gmail.com. 


\section{Introdução}

O presente artigo é resultado de uma pesquisa de ação conjunta entre o Centro de Referência Técnica em Psicologia e Políticas Públicas - CREPOP ${ }^{5}$, o Setor de Comunicação Social $^{6}$ e a Área Técnico-Fiscal ${ }^{7}$ do Conselho Regional de Psicologia do Rio Grande do Sul (CRPRS). A construção inicial desse projeto, formulada no ano de 2009, partiu de uma proposta assumida através do CREPOP do CRPRS, aprovada pelo Sistema Conselhos de Psicologia $^{8}$, de desenvolvimento de uma pesquisa local voltada para a realização de uma análise das publicações que vinham sendo veiculadas na mídia gaúcha sobre a temática do álcool e outras drogas.

O CREPOP é uma ferramenta do Sistema Conselhos de Psicologia que foi desenvolvida a partir da necessidade de maior aproximação do Conselho de Psicologia com a ação profissional do psicólogo junto às políticas públicas. O CREPOP atua, principalmente, na construção de referências técnicas através de pesquisas nacionais, realizadas regionalmente. Além destas pesquisas, os Centros de Referência são incentivados pelo Núcleo Nacional ${ }^{9}$ à construção de pesquisas regionais, relacionadas a temáticas concernentes às políticas públicas, a partir de demandas específicas dos estados aos quais estão vinculados. Nesse sentido, situa-se nesse contexto a formulação da proposta inicial desse estudo.

Posteriormente, o Setor de Comunicação e a Área Técnico-Fiscal passaram a compor a construção da pesquisa, agregando diferentes olhares e saberes ao projeto. A partir disso, a pesquisa adquiriu um caráter ampliado se constituindo como uma ação intersetorial dentro do CRPRS. Durante o desenvolvimento da pesquisa ocorreu, ainda, a oportunidade de obter a colaboração voluntária de uma pesquisadora sobre o tema, aluna do mestrado ${ }^{10} \mathrm{em}$ Psicologia Social e Institucional da Universidade Federal do Rio Grande do Sul.

A temática do álcool e drogas emergiu como uma importante pauta para o Sistema Conselhos de Psicologia no VI Congresso Nacional de Psicologia. A partir disso, a rede CREPOP desenvolveu, em 2009, uma pesquisa nacional sobre a atuação do psicólogo nas

\footnotetext{
${ }^{5}$ Participaram do desenvolvimento da pesquisa pelo CREPOP: as(o) presentes autoras(o).

${ }^{6}$ Participaram do desenvolvimento da pesquisa pelo Setor de Comunicação Social: Belisa Giorgis e Nádia Miola.

${ }^{7}$ A Área Técnica do CRPRS é composta por psicólogos/as fiscais e técnicos/as e está à disposição da categoria e da sociedade para orientação. E-mail orientec@crprs.org.br.

${ }^{8}$ O Sistema Conselhos de Psicologia é o conjunto composto pelo Conselho Federal de Psicologia e pelos Conselhos Regionais de Psicologia. A proposta da pesquisa foi apresentada e aprovada na Assembleia de Políticas Administrativas e Finanças - APAF, reunião em que são definidas as diretrizes políticas, administrativas e financeiras para o Sistema Conselhos de Psicologia.

${ }^{9}$ O Centro de Referência Técnica em Psicologia e Políticas Públicas está estruturado em Rede, com uma instância de Coordenação Nacional, sediada no Conselho Federal de Psicologia, e com 19 unidades locais, sediadas nos Conselhos Regionais.

${ }^{10}$ A pesquisa contou com a colaboração de uma participante, mestra em Psicologia Social e Institucional pela UFRGS, Mariane Hartmann.
} 
políticas públicas para o álcool e outras drogas. Ainda naquele ano, o Sistema Conselhos de Psicologia esteve comprometido com os debates em torno da Comunicação Social. Isso se refletiu na organização de uma comissão nacional e de outras regionais responsáveis, dentre outras atividades, pela promoção de espaços de discussão como palestras e seminários sobre temas relevantes para a Psicologia e a forma como estes circulam e são apresentados na mídia. Essas ações tornaram mais presente para a categoria profissional a importância da mídia como um veículo através do qual são produzidas determinadas verdades sobre questões que atravessam as práticas dos psicólogos (TORRES; ECKER, 2017).

A proposta de desenvolvimento do estudo que resultou neste material emerge atrelada a esses movimentos e tem por objetivo afirmar a importância da Psicologia e, em especial, dos atores envolvidos na formulação e execução de políticas públicas de se lançarem em uma reflexão sobre o que vem sendo veiculado pela mídia sobre álcool e outras drogas.

No Rio Grande do Sul essa temática esteve fortemente presente nos veículos de comunicação, tendo como efeito a inclusão desse assunto na pauta dos diálogos cotidianos dos gaúchos. Um dos visíveis efeitos produzido na opinião pública é que o uso de drogas se tornou uma preocupação para toda a sociedade rio-grandense, tornando-a mais atenta e sensibilizada à condução das políticas públicas e demais ações do Estado voltadas tanto para o tratamento de usuários de drogas, quanto para medidas de segurança urbana e de repressão ao tráfico de entorpecentes. Esses acontecimentos emergem concomitantes a um período de fortes embates na cena política que coloca em questão importantes conquistas do Movimento Sanitarista e da Reforma Psiquiátrica no que se refere à construção de modelos de tratamento em saúde mental pautados pela garantia dos direitos dos portadores de sofrimento psíquico, entendidos dentre esses os usuários de drogas (REIS, 2012).

Nesse sentido, a construção de uma pesquisa como essa não parte de uma lógica de neutralidade, pelo contrário, a postura que se assume está implicada com a garantia das políticas de saúde mental, das políticas para álcool e outras drogas e com o Programa de Redução de Danos preconizados pelo Ministério da Saúde (BRASIL, 2003; BRASIL, 2005). Sendo o Rio Grande do Sul um estado pioneiro da promulgação da lei da Reforma Psiquiátrica de 1992, o CRPRS está atento e implicado em reafirmar os princípios da luta antimanicomial frente ao movimento de contra reforma que têm emergido e se fortalecido nos últimos anos no estado (SANTOS, 2010). 


\section{Mídia e Produção de Subjetividades}

Quando se coloca a mídia como foco central de análise é por compreender os meios de comunicação como poderosos veículos de circulação e produção de uma série de valores, concepções, relacionadas a um aprendizado cotidiano de quem nós somos. Para Coimbra (2001a), a mídia é um dos mais importantes equipamentos sociais por produzir esquemas dominantes de significação e interpretação do mundo. A mídia pauta os temas presentes no cotidiano sobre os quais, supostamente, deveríamos pensar e nos posicionar. Ainda, segundo a autora, a mídia forja modos de sentir, pensar, perceber e agir. Sendo assim, a mídia opera na construção de identidades individuais e sociais, bem como na produção social de inclusões, exclusões e diferenças. Nesse sentido, entende-se a mídia, de acordo com Fischer (2002), como um local de veiculação de discursos e produção de sentidos, os quais estão associados aos modos como nos relacionamos com o mundo.

Colocar em análise esse modo de produção de subjetividades, que opera através das mídias, implica, conforme analisado por Coimbra (2001a), negar a concepção dos modos de ser no mundo como algo natural ou relacionado às essencializações; abster-se de naturalizações do cotidiano nos coloca a necessidade de evidenciar a fabricação dessas formas de habitar a contemporaneidade, afirmando-as como datadas historicamente e situadas dentro de um contexto político, econômico e cultural.

É importante destacar que o efeito da mídia na produção de subjetividades está atrelado à construção da mídia como um lugar em que se diz "a verdade" (COIMBRA, 2001a). Ao afirmarmos isso buscamos a realização de uma análise crítica que permita nos afastarmos da noção de verdade como algo absoluto, neutro e universal e passarmos a situar a verdade no interior de jogos de força de natureza política. A verdade seria, portanto, um campo de negociação sempre em disputa (FOUCAULT, 2009). Entretanto, os meios de comunicação, ao apresentar determinados enunciados, o fazem de forma a obscurecer o processo de fabricação desses enunciados enquanto verdade e os afirmam como a descoberta de algo natural. Assim, se propõe evidenciar esses jogos de produção de verdades nos quais estão inseridos os discursos da mídia sobre o álcool e as outras drogas, buscando analisar os possíveis efeitos nos modos como os sujeitos passam a agir e se posicionar frente às drogas, aos usuários de drogas e à condução das políticas públicas direcionadas a essa temática.

\footnotetext{
Além de produzir modos de existência e de vida, de estar nas mãos de poucos, a mídia funciona organizando diversos e diferentes fluxos de acontecimentos; pela via do espetáculo, das formas dramáticas e sensacionalistas produz identidades, simpatia, prós e contras. À medida, portanto, que organiza os múltiplos fluxos de acontecimentos, a mídia hierarquiza os temas, selecionando os que deverão ser do conhecimento público e, daí, os que deverão necessariamente ser discutidos, debatidos, pensados (COIMBRA, 2001b, p. 36).
} 
Outra estratégia utilizada pela mídia na produção de modos de agir e pensar está relacionada à lógica da homogeneização, fundada em uma linguagem factográfica e dicotômica que apresenta unicamente dois lados, o bom e o mau, ofuscando a complexidade dos acontecimentos. Além disso, apesar de apresentar os ditos fatos de forma fragmentada, buscam produzir uma racionalidade linear em termos de causas e efeitos. Ainda, o uso da estratégia do espetáculo como forma de afetar também as emoções do público. (COIMBRA, 2001b). Essas são algumas ferramentas utilizadas pela mídia para a fabricação de fatos, para a legitimação destes enquanto verdades que pautarão a produção de racionalidades e condutas. No que se refere à temática em foco neste artigo:

Estudos realizados no âmbito nacional apontam que a mídia adota uma política de combate às drogas, sustentada por uma visão estritamente jurídica de ilegalidade, utilizando-se de linguagem repressora, cuja mensagem não consiste em informar, mas sim convencer o leitor, limitando a possibilidade de elaboração de uma concepção própria por parte deste (SOUZA; OLIVEIRA, 2009, p. 146).

\section{Procedimentos Metodológicos}

Para o desenvolvimento do presente estudo foram selecionadas publicações dos três jornais impressos de maior circulação pelo estado do Rio Grande do Sul, sendo eles: Correio do Povo, Jornal do Comércio e Zero Hora. A escolha desses veículos de comunicação se deu, ainda, por serem dirigidos às classes médias urbanas. A seleção teve como foco o período de maio a julho de 2009, quando do início do desenvolvimento da proposta da pesquisa. A coleta do material foi desenvolvida pela equipe de Comunicação Social do CRPRS que realizou a clipagem dos jornais. Em um primeiro momento foram selecionadas todas as publicações que se remetiam direta ou indiretamente a temática de álcool e outras drogas, mesmo que de forma bastante genérica. Para tanto foi realizada uma busca visual nos materiais de cada edição dos três jornais, disponibilizados nas bases de dados virtuais desses veículos midiáticos. Optou-se pela realização de uma cuidadosa busca visual por entendermos ser esta a forma mais confiável e completa de identificação das publicações que se adequavam aos critérios estabelecidos na pesquisa. Nessa primeira etapa foi coletado um total de 748 publicações.

Devido ao grande volume de materiais para análise, no segundo momento da pesquisa, foram descartadas as publicações que diziam respeito a materiais publicitários como divulgação de cursos e aquelas em que a palavra droga não se referia a álcool, tabaco ou a substâncias psicoativas ilícitas, mas admitiam outros significados como um sinônimo para medicamento, por exemplo. Desta primeira seleção restaram ainda 686 publicações. Posteriormente, separamos os materiais por veículo midiático e por mês, trabalhando com uma amostra igual de cada jornal e dos três períodos selecionados. A partir disso utilizamos o critério de saturação dos dados, resultando em uma amostra final de 270 publicações, sendo 
90 de cada jornal e destes 30 de cada um dos meses de maio, junho e julho como demonstra a amostra dos jornais estudados (Tabela 1).

Tabela 1 - Amostra dos jornais estudados

\begin{tabular}{l|c|c|c|c|c|c|c|c|c}
\hline Veículo & \multicolumn{3}{|c|}{ Correio do Povo } & \multicolumn{2}{c|}{ Jornal do Comércio } & \multicolumn{3}{c}{ Zero Hora } \\
\hline Mês & Maio & Junho & Julho & Maio & Junho & Julho & Maio & Junho & Julho \\
& 30 & 30 & 30 & 30 & 30 & 30 & 30 & 30 & 30 \\
\hline Totais & \multicolumn{3}{|c|}{90 publicações } & \multicolumn{3}{c|}{90 publicações } & \multicolumn{2}{c}{90 publicações } \\
\hline
\end{tabular}

Total Final: 270

Fonte: Setor de Comunicação do CRP-07.

Todas essas 270 publicações foram impressas e catalogadas através do instrumento exibido a seguir (Figura 1). Este instrumento foi criado pelo setor de Comunicação Social e tem como intuito dar visibilidade a alguns elementos jornalísticos que destacam a relevância da reportagem e os lugares que são atribuídos a ela dentro do jornal. Isto é, elementos que colocam em análise a forma como a mídia se dirige ao seu público alvo, os recursos de persuasão dos leitores em relação às afirmações apresentadas nas matérias jornalísticas. Deste instrumento foram levantados dados quantitativos, que serão apresentados e analisados posteriormente.

Figura 1 - Instrumento de catalogação das reportagens coletadas

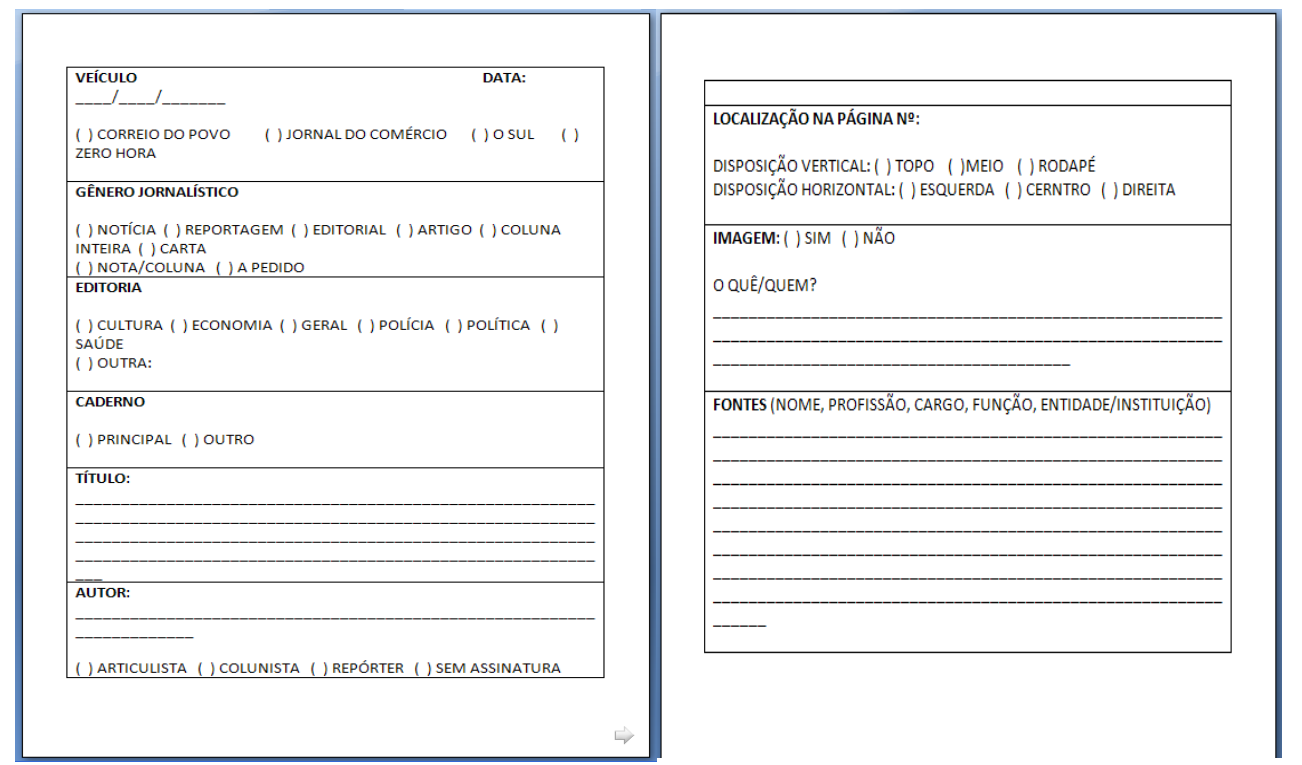

Fonte: Setor de Comunicação do CRP-07. 
Após essa catalogação, criou-se um segundo instrumento para orientar a análise do conteúdo das reportagens. Nesse segundo instrumento foram elencadas perguntas norteadoras na análise dos materiais. As perguntas norteadoras tiveram por base os objetivos da pesquisa, conforme ilustrado na Figura 2:

Figura 2 - Instrumento de orientação para análise do conteúdo das reportagens

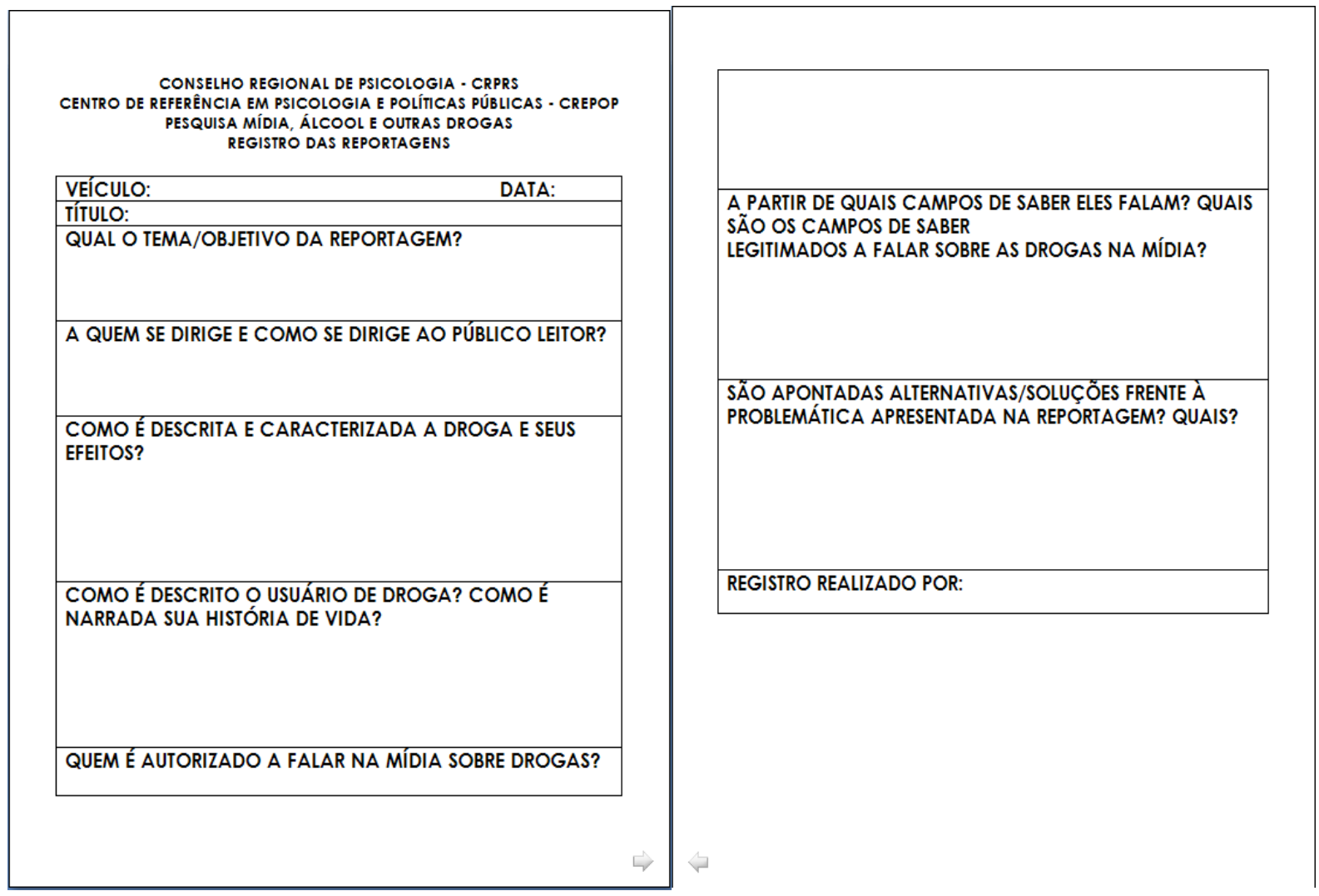

Fonte: CREPOP do CRP-07.

Assim, após a coleta do material, organização das reportagens e análise dos seus conteúdos, de acordo com as questões do instrumento, foi possível colocar em evidência os discursos vinculados à temática do álcool e outras drogas nas mídias estudadas. A seguir, serão apresentados os resultados obtidos. Em um primeiro momento, serão visibilizados os contextos em que emergem as entrevistas, os gêneros jornalísticos em que as reportagens se encontram em cada mídia, a distribuição por editoria (sessão) e caderno em que elas foram divulgadas, o modo de autoria, a localização na página, o uso de imagens e as fontes citadas. Essas configurações tornam-se relevantes para a discussão, visto que a diagramação das reportagens também é entendida como possíveis ferramentas estratégicas no processo de produção de verdades sobre a temática em questão.

Em seguida, serão apresentados os conteúdos das reportagens que foram organizados de acordo com as questões do instrumento de orientação para análise (Figura 2). Estes, 
resultaram em 5 (cinco) principais categorias que possibilitam colocar de forma didática as racionalidades que se atravessam nos processos de produção de verdades sobre o álcool e as outras drogas, são elas: 1) Drogas: "entidades” de vida própria; 2) Usuários: perigosos; 3) Quem fala na mídia: os "especialistas"; 4) Campos de saber; 5) Soluções apontadas: higienismo e repressão.

\section{Resultados}

\subsection{Dados jornalísticos}

\subsubsection{Distribuição por gênero jornalístico}

Figura 3 - Distribuição das reportagens por gênero jornalístico

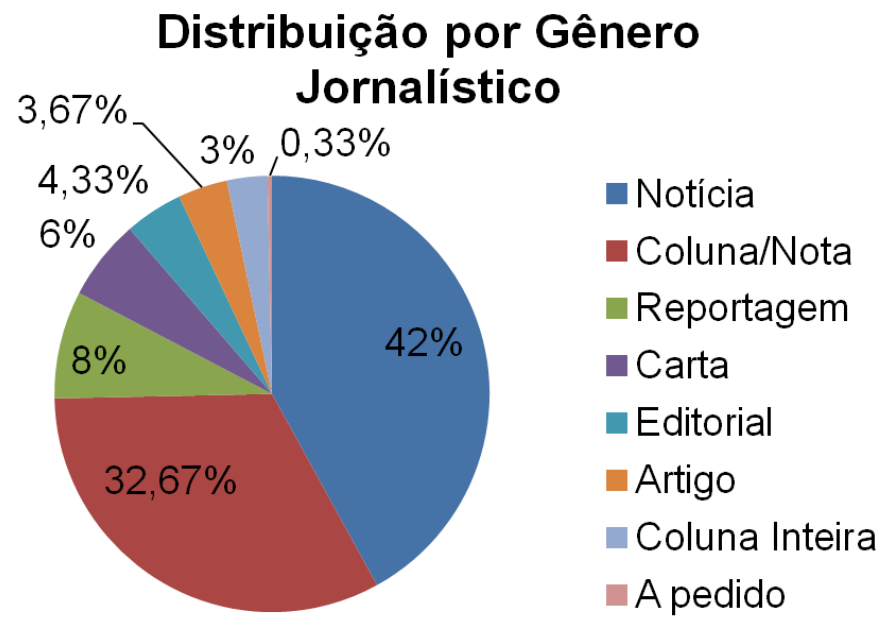

Fonte: Setor de Comunicação do CRP-07. 
Tabela 2 - Distribuição do gênero jornalístico por veículo midiático

\begin{tabular}{l|c|c|c}
\hline Gênero Jornalístico & Correio do Povo & Jornal do Comércio & Zero Hora \\
\hline Notícia & $55 \%$ & $35 \%$ & $36 \%$ \\
\hline Reportagem & $0 \%$ & $11 \%$ & $13 \%$ \\
\hline Editorial & $3 \%$ & $1 \%$ & $9 \%$ \\
\hline Artigo & $0 \%$ & $2 \%$ & $9 \%$ \\
\hline Coluna inteira & $1 \%$ & $0 \%$ & $8 \%$ \\
\hline Coluna/nota & $37 \%$ & $50 \%$ & $11 \%$ \\
\hline Carta & $4 \%$ & $1 \%$ & $1 \%$ \\
\hline A pedido & $0 \%$ & $0 \%$ & $13 \%$ \\
\hline
\end{tabular}

Fonte: Setor de Comunicação do CRP-07.

Nesse tópico destaca-se a presença da temática do álcool e outras drogas como foco de notícia, isto é, como tema que adquire visibilidade tornando-se algo a ser noticiado cotidianamente. Nesse sentido, se esse tema é foco de notícia, passa a ser, da mesma forma, assunto para as notas e colunas de especialistas e formadores de opinião das mais diversas áreas. Na tabela, nas regiões destacadas em cor verde, é possível identificar as especificidades mais frequentes de gênero jornalístico em cada uma das mídias.

\subsubsection{Distribuição por editoria}

Figura 4 - Distribuição das reportagens por editoria (sessão)

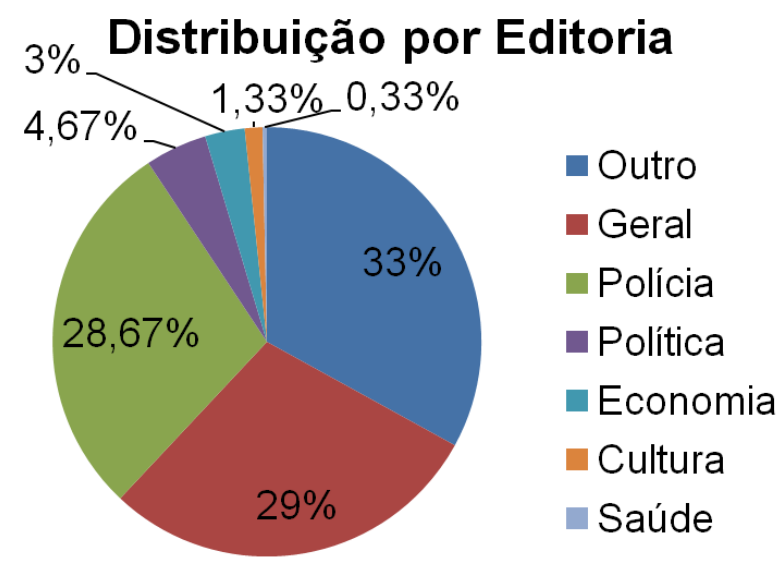

Fonte: Setor de Comunicação do CRP-07. 
Tabela 3 - Distribuição das reportagens por editoria (sessão) em cada veículo midiático

\begin{tabular}{l|c|c|c}
\hline \multicolumn{1}{c|}{ Editoria } & Correio do Povo & Jornal do Comércio & Zero Hora \\
\hline Outra & $26 \%$ & $32 \%$ & $41 \%$ \\
\hline Política & $2 \%$ & $7 \%$ & $5 \%$ \\
\hline Saúde & $0 \%$ & $0 \%$ & $1 \%$ \\
\hline Polícia & $42 \%$ & $17 \%$ & $27 \%$ \\
\hline Economia & $0 \%$ & $6 \%$ & $3 \%$ \\
\hline Geral & $30 \%$ & $34 \%$ & $23 \%$ \\
\hline Cultura & $0 \%$ & $4 \%$ & $0 \%$ \\
\hline
\end{tabular}

Fonte: Setor de Comunicação do CRP-07.

Nesse item identifica-se que as publicações sobre o álcool e outras drogas adquirem destaque no caderno geral dos jornais, que é um dos espaços de grande visibilidade, e na categoria outros, mostrando como esse é um tema que passa a ser falado relacionado a uma diversidade de questões como, por exemplo, arte, educação, trânsito e esportes. Além disso, neste tópico, evidencia-se o quanto essa temática se torna um assunto de polícia, especialmente, no jornal Correio do Povo, que enfatiza essa relação das drogas com a criminalidade e as ações policiais investidas contra o tráfico. Já o jornal Zero Hora, apresenta mais publicações vinculadas à categoria outros, pois seu foco de debate concentra-se mais na figura do usuário de drogas e nas consequências do uso. Esta mídia discorre suas reportagens, principalmente, colocando essa temática como uma questão que deveria ser debatida e enfrentada por toda a sociedade. Como grifado em cor laranja na Tabela 3, evidencia-se a ausência de reportagens sobre o álcool e outras drogas nas sessões editoriais relacionadas à saúde, evidenciando como esse tema se torna notícia ainda vinculado às questões relacionadas à violência e a criminalidade. 


\subsubsection{Distribuição por caderno}

Figura 5 - Distribuição das reportagens por caderno

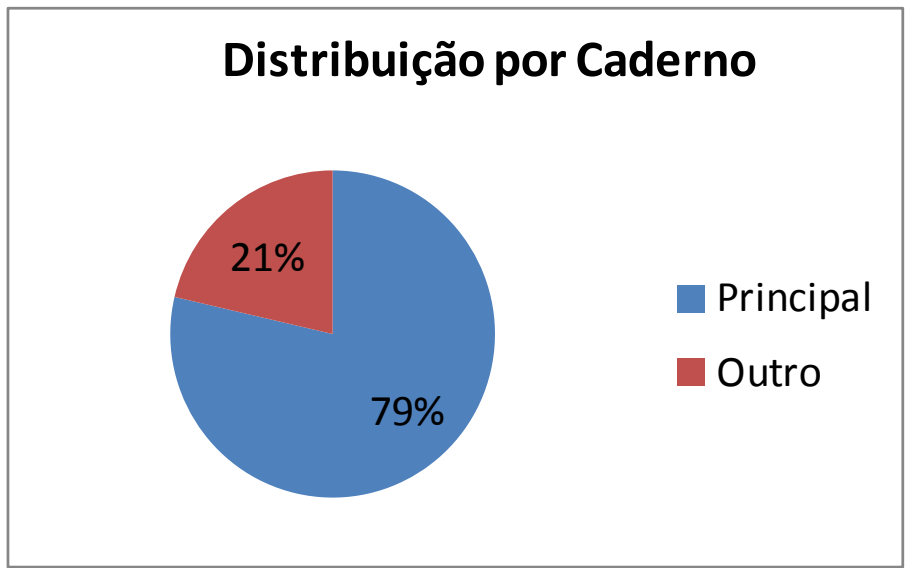

Fonte: Setor de Comunicação do CRP-07.

Tabela 4 - Distribuição das reportagens por caderno em cada veículo midiático

\begin{tabular}{l|c|c|c}
\hline Caderno & Correio do Povo & Jornal do Comércio & Zero Hora \\
\hline Principal & $91 \%$ & $68 \%$ & $77 \%$ \\
\hline Outro & $9 \%$ & $32 \%$ & $23 \%$ \\
\hline
\end{tabular}

Fonte: Setor de Comunicação do CRP-07.

Majoritariamente, as publicações vinculadas a álcool e outras drogas foram encontradas no caderno principal, o que demonstra a relevância do tema. No Jornal do Comércio, observa-se um elevado número de publicações sobre o tema em outros cadernos, que não o principal. Elas, no geral, situam-se no caderno "Cidades" que trazem notícias de acontecimentos dos municípios da região metropolitana e do interior do Estado do Rio Grande do Sul. 


\subsubsection{Distribuição por autor}

Figura 5 - Distribuição das reportagens por tipo de autoria

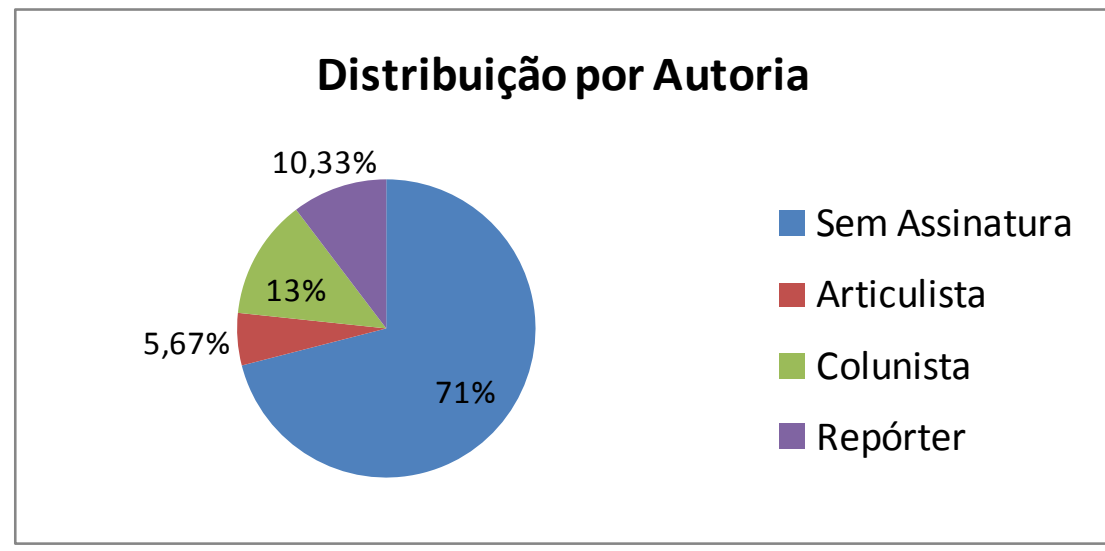

Fonte: Setor de Comunicação do CRP-07.

Tabela 5 - Distribuição das reportagens por tipo de autoria em cada veículo midiático

\begin{tabular}{l|c|c|c}
\hline \multicolumn{1}{c|}{ Autor } & Correio do Povo & Jornal do Comércio & Zero Hora \\
\hline Sem assinatura & $95 \%$ & $67 \%$ & $51 \%$ \\
\hline Articulista & $0 \%$ & $4 \%$ & $13 \%$ \\
\hline Colunista & $4 \%$ & $25 \%$ & $10 \%$ \\
\hline Repórter & $1 \%$ & $4 \%$ & $26 \%$ \\
\hline
\end{tabular}

Fonte: Setor de Comunicação do CRP-07.

Como a grande maioria das publicações é no formato de notícias, em geral, não há assinatura. A ausência de uma assinatura dialoga com um modelo de divulgação da informação como fato, como se a notícia fosse isenta de responsabilidades e pudesse sem escrita da mesma forma por qualquer sujeito. Nesse sentido, como se destaca pela cor verde na Tabela 5, a isenção de autoria se fez presente na maior parte das reportagens encontradas. Essa característica resulta na produção de uma informação desresponsabilizada já que o leitor não tem a quem recorrer caso queira estabelecer uma crítica ao conteúdo ou saber de qual contexto escreve o autor. 


\subsubsection{Distribuição por localização na página}

Figura 6 - Distribuição das reportagens por localização na página

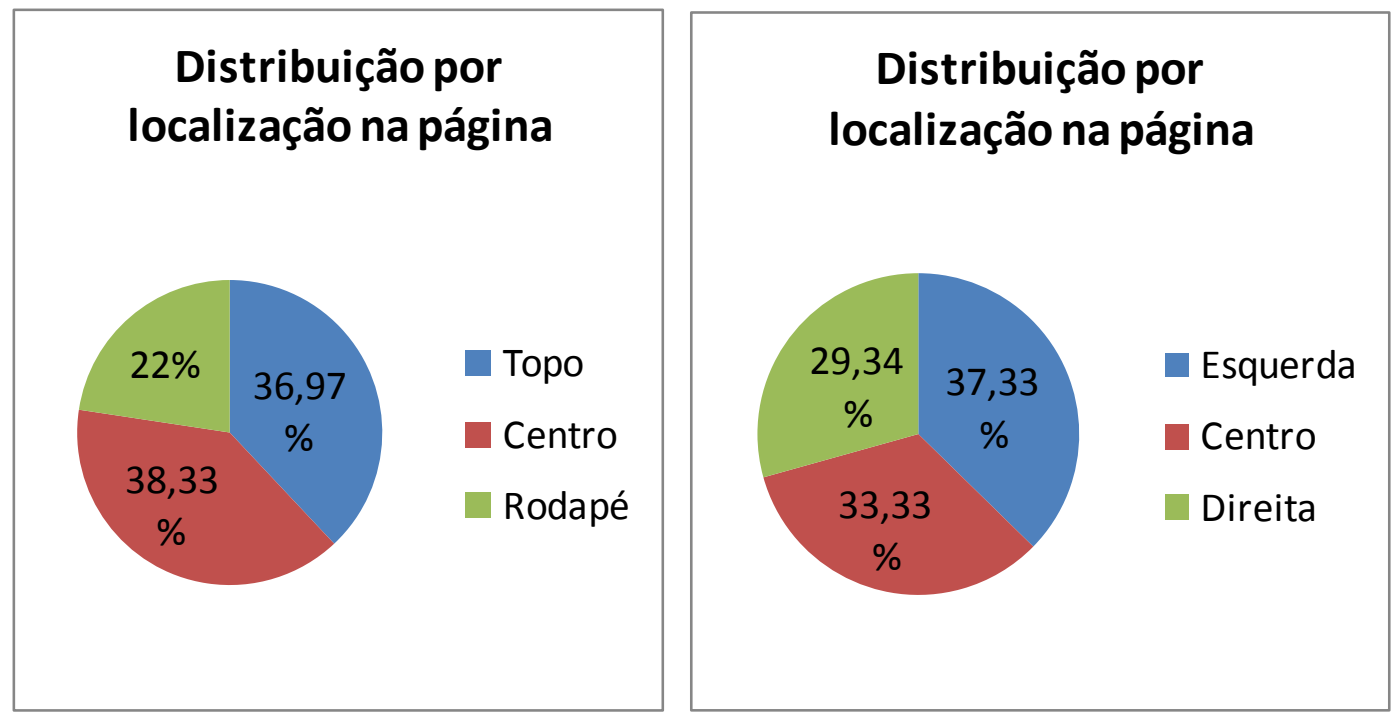

Fonte: Setor de Comunicação do CRP-07.

Tabela 6 - Distribuição por localização na página em cada veículo midiático

\begin{tabular}{l|c|c|c}
\hline $\begin{array}{l}\text { Localização na } \\
\text { Página }\end{array}$ & Correio do Povo & Jornal do Comércio & Zero Hora \\
\hline Topo & $30 \%$ & $43 \%$ & $49 \%$ \\
\hline Centro & $48 \%$ & $33 \%$ & $34 \%$ \\
\hline Rodapé & $22 \%$ & $24 \%$ & $20 \%$ \\
\hline Esquerda & $39 \%$ & $43 \%$ & $30 \%$ \\
\hline Centro & $33 \%$ & $25 \%$ & $42 \%$ \\
\hline Direita & $28 \%$ & $32 \%$ & $28 \%$ \\
\hline
\end{tabular}

Fonte: Setor de Comunicação do CRP-07.

A presença das publicações nas páginas se dá de forma bem distribuída, entretanto, mantém a predominância de publicações no topo e centro dos jornais, em detrimento do rodapé, como destacado na tabela pela cor verde. Da mesma forma, há predominância dos conteúdos nos espaços a esquerda da página e centro, que são considerados espaços de maior visibilidade na disposição gráfica das informações no jornal impresso, o que demonstra o local de destaque que o tema de álcool e outras drogas adquiriram na imprensa gaúcha nesse período. 


\subsubsection{Distribuição por presença de imagem}

Figura 7 - Distribuição das reportagens por presença de imagem

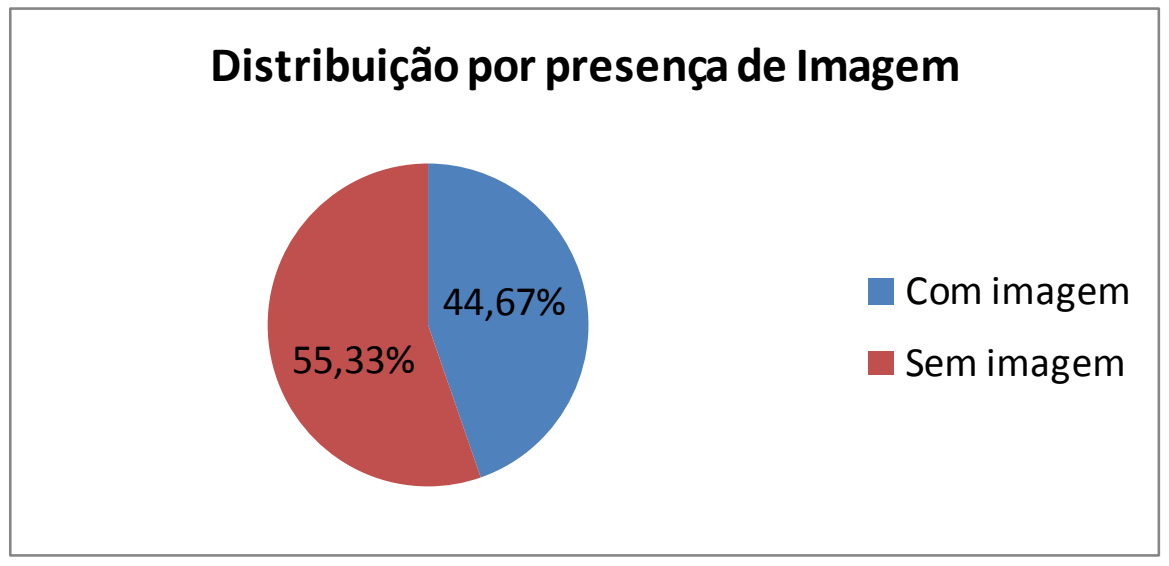

Fonte: Setor de Comunicação do CRP-07.

Tabela 7 - Distribuição por presença de imagem em cada veículo midiático

\begin{tabular}{c|c|c|c}
\hline \multicolumn{1}{c|}{ Imagem } & Correio do Povo & Jornal do Comércio & Zero Hora \\
\hline Com Imagem & $49 \%$ & $32 \%$ & $53 \%$ \\
\hline Sem Imagem & $51 \%$ & $68 \%$ & $47 \%$ \\
\hline
\end{tabular}

Fonte: Setor de Comunicação do CRP-07.

Observa-se uma paridade em relação ao número de publicações que contém imagens em relação àquele número que não contém, à exceção do Jornal do Comércio que apresenta um número maior de publicações sem imagem. Entretanto, de maneira geral, o Jornal do Comércio é um jornal que traz mais textos e menos imagens em todas as notícias, independente da temática, diferente dos demais. 


\subsubsection{Distribuição por Fontes}

Figura 7 - Distribuição das reportagens por fontes citadas

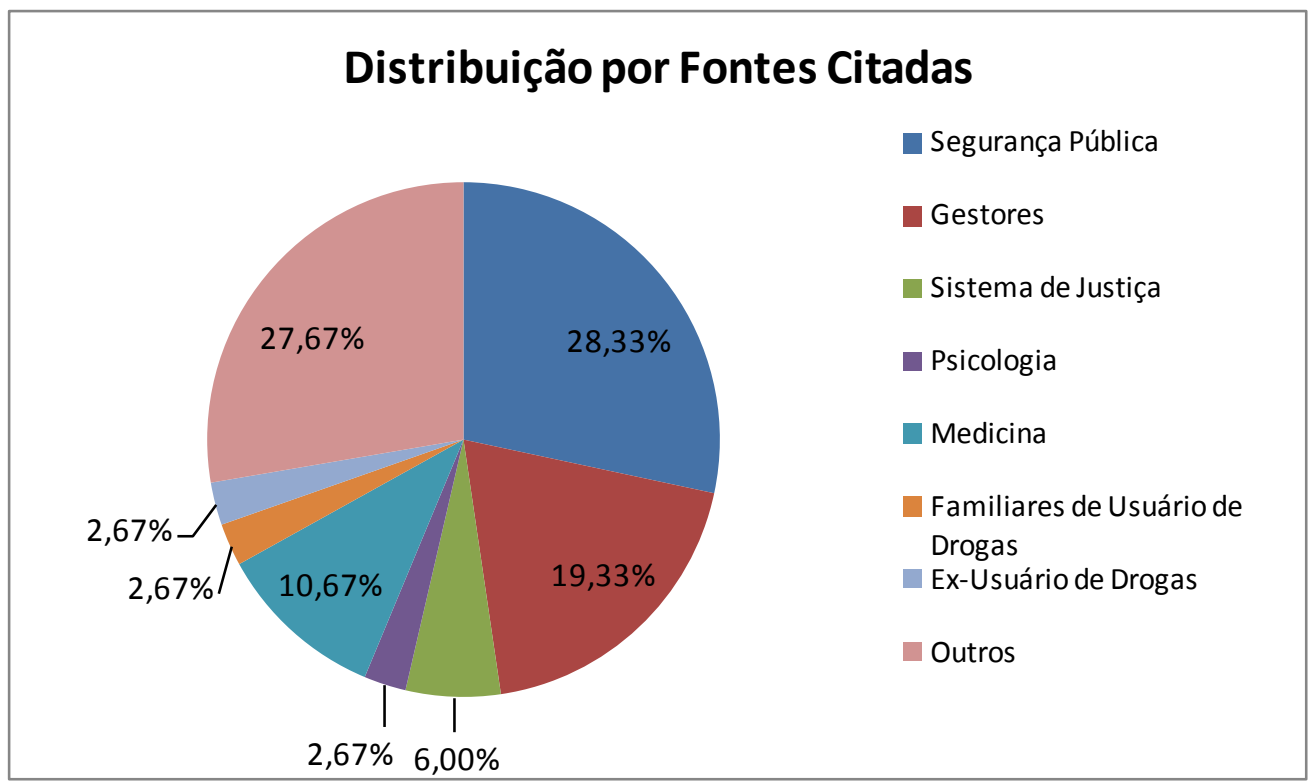

Fonte: Setor de Comunicação do CRP-07.

Tabela 8 - Distribuição por fontes citadas em cada veículo midiático

\begin{tabular}{l|c|c|c}
\hline \multicolumn{1}{c|}{ Fontes Citadas } & Correio do Povo & Jornal do Comércio & Zero Hora \\
\hline Seg. Pública & $49 \%$ & $10 \%$ & $26 \%$ \\
\hline Gestores & $18 \%$ & $32 \%$ & $8 \%$ \\
\hline Sist. Justiça & $4 \%$ & $11 \%$ & $3 \%$ \\
\hline Psicologia & $1 \%$ & $4 \%$ & $3 \%$ \\
\hline Med./Psiquiatria & $9 \%$ & $9 \%$ & $14 \%$ \\
\hline Familiares & $0 \%$ & $0 \%$ & $8 \%$ \\
\hline Ex-usuários & $1 \%$ & $4 \%$ & $3 \%$ \\
\hline Outros & $18 \%$ & $30 \%$ & $35 \%$ \\
\hline
\end{tabular}

Fonte: Setor de Comunicação do CRP-07.

$\mathrm{Na}$ distribuição por fontes citadas, foram considerados aqueles sujeitos que são entrevistados pelo jornal na construção das notícias e reportagens nas quais suas falas e cargos ganham local de destaque na construção do texto. Nesse quesito, destacamos na tabela a diferença entre os veículos de comunicação na cor verde. O Correio do Povo dá um destaque maior para os agentes da segurança pública e instituições policiais. Já o Jornal do Comércio 
traz bastantes falas de gestores e representantes do legislativo, que dialoga com publicações que trazem mais o tema da gestão e implantação de políticas públicas, incluídas nessas as políticas de saúde e segurança pública e na Zero Hora a presença de outras fontes, principalmente dos ditos especialistas. Na cor laranja, evidencia-se baixa presença dos profissionais da Psicologia como fonte de referência e de fala sobre o álcool e as outras drogas.

\subsection{Produções de discursos nos conteúdos das reportagens}

Após o mapeamento dos dados jornalísticos foi realizado a análise dos conteúdos abordados em cada matéria objetivando conhecer os discursos divulgados pelas mídias sobre o tema de álcool e outras drogas. A partir dos escritos encontrados foi possível categorizar os achados em 5 (cinco) principais pontos.

\subsubsection{Drogas: "entidades" de vida própria.}

Nos materiais jornalísticos as drogas são referidas quase como entidades de vida própria, como uma substância que agiria sobre os indivíduos e suas ações e podendo, sozinha, "destruir vidas". Ignora-se a existência de um sujeito responsável pelo consumo da droga, isto é, de um sujeito que interage com a substância, faz escolha e toma decisões. Ignora-se, ainda, aqueles casos em o uso de drogas ocorre sem que isso acarrete em prejuízo significativo para a vida dos usuários.

Da forma como são apresentadas nas publicações em foco, as drogas emergem enquanto algo que possui o poder de anular o sujeito. Ainda, nesse contexto, as substâncias são apresentadas como algo totalizante, que se encerram em si, como se elas fossem o motivo que levou ao uso, as responsáveis pela dependência e pelo agravamento das condições de vida desses sujeitos.

Abaixo destacamos aquelas temáticas que aparecem vinculadas ao tema do álcool e das outras drogas nas publicações da mídia e que adquirem esse tom alarmista quanto aos efeitos causados por essas substâncias:

1. Aumento da violência e das taxas de homicídio: as drogas são indicadas como algo que produz o aumento na violência urbana gerada tanto pelo comércio de substâncias ilícitas, quanto indicando os riscos a que são expostas pessoas que são vítimas da violência praticada por indivíduos sob o efeito de alguma substância psicoativa, principalmente em relação ao uso do crack.

2. Aumento da criminalidade: principalmente relacionado ao tráfico de drogas e ao contrabando de armas. 
3. As drogas são apresentadas também como um problema de Saúde Pública: enquanto tal é frequente a presença de materiais midiáticos que indicam os efeitos físicos e psíquicos do uso de drogas, vinculados a uma descrição desumanizada do usuário. Essa última caracterizase pelo uso de expressões como: "torna-se um animal", "deixa de ser humano", "ficam desfigurados", "perde a capacidade de amar", entre outros.

4. Como um problema para a Educação: relacionado tanto ao anúncio das drogas como algo que está invadindo as escolas, que é comercializado ilegalmente dentro das salas de aula ou na porta das escolas, quanto em relação ao abandono escolar provocado pelo uso continuado e abusivo de substâncias psicoativas.

5. Mobilização do Poder Público: as drogas são indicadas como algo que tem gerado gastos com saúde pública e produzido uma grande confusão nos serviços, que não estariam preparados para o atendimento de usuários de drogas. Interessante destacar que os recursos gastos com segurança pública não são indicados como gastos, mas como investimentos, enquanto na saúde esses valores são indicados como um desperdício de recursos públicos.

6. Problema Social: as drogas emergem como um problema social quando passam a produzir insegurança e medo atrelado ao discurso alarmante a cerca do aumento da violência.

7. Problema Familiar: como algo que invade as casas e dizima famílias. Ignoram-se as possíveis implicações da família nos motivos que levaram o sujeito ao uso abusivo de drogas ou aos conflitos que já existiam anteriormente no interior das famílias e apontam-se as drogas como a grande produtora das nomeadas desestruturações familiares.

8. Relacionada à pobreza: o uso e comercialização de substâncias aparecem nas produções midiáticas vinculadas a determinados territórios das periferias da cidade, como se o uso não ocorresse em outras classes sociais, territórios ou nos grupos economicamente privilegiados.

9. Outros: em poucos momentos as drogas adquirem outras conotações na mídia, como algo que pode proporcionar prazer, que traz dinheiro aos traficantes ou que serve de sustento às famílias pobres.

\subsubsection{Os Usuários: perigosos}

O segundo ponto a ser destacado aborda o modo como a mídia discorre sobre a temática de álcool e as outras drogas relacionando a descrição dos usuários de substâncias a sujeitos potencialmente perigosos. Ainda que apareçam outras caracterizações, a noção de periculosidade associada àqueles que fazem uso de drogas permanece como algo dominante nos discursos das publicações analisadas. A seguir, aponta-se 9 (nove) indicadores que estão presentes nos sentidos produzidos pela mídia impressa sobre quem é esse sujeito que faz uso de drogas, o que podemos esperar dele e como devemos agir em relação a eles: 
1. Doentes: a dependência química é apresentada como uma doença que deixaria o usuário sem condições de decidir sobre seu tratamento. Esse discurso reforça a ideia de que a única forma de atenção em saúde possível é a internação compulsória ou involuntária.

2. Criminosos: sujeitos que roubam para poder consumir mais drogas. Em geral existe uma descrição bastante moralizada que vai caracterizar esses indivíduos como pessoas supostamente más e opostas aos "bons cidadãos".

3. Vítimas: quando apontados como vítimas, em geral, estão relacionados à descrição de crianças que passam a fazer o uso de drogas. Nesses casos, os sujeitos passam a ser identificados como: pessoa sem informação, indefesa e que necessitaria de proteção e orientação.

4. Violentos: o usuário de droga é descrito como um sujeito que não consegue controlar seus atos, que se torna facilmente agressivo, que passa a ser capaz de agredir qualquer pessoa. Essas descrições vêm em tom alarmante indicando o suposto nível de periculosidade de sujeitos que fazem uso de drogas.

5. Sem educação e sem trabalho: essas indicações auxiliam na construção de um quadro que os coloca no lugar de sujeitos marginalizados/fora/contra uma determinada estrutura de ordem social baseada na produção do trabalho.

6. Pobres: descritos como pessoas que reviram lixo, que vivem junto à sujeira, poeira, sem higiene, mendigos, desabrigados, entre outros.

7. Ricos: quando fazem referência a artistas, filhos de políticos e turistas.

8. Sem solução ou recuperados: em geral, nessa categoria, são apontadas as descrições de sujeitos sem recuperação. Entretanto, em contraponto, são vinculadas às citações e exemplos de sujeitos que estão abstinentes; construindo para o leitor a ideia de que esses últimos seriam indicados como exemplos de que é possível deixar de fazer uso de drogas, desde que haja um engajamento do sujeito na busca pela "cura".

9. Inconsequentes: que estariam buscando o prazer e colocando os outros em risco por simples vontade ou descontrole.

\subsubsection{Quem fala na Mídia: Os "especialistas"}

Ao se olhar para a forma como a mídia se apresenta nos meios de comunicação identificam-se, como terceiro ponto de análise, os sujeitos que falam sobre a temática. Essa categoria de discussão foi levantada, visto a importância de se identificar os grupos nos quais os meios de comunicação disponibilizam espaços de fala e julgam como relevantes para informar a população sobre os assuntos que envolvem a temática do álcool e as outras drogas. No gráfico abaixo (Figura 8) se evidenciam os resultados encontrados: 


\section{Figura 8 - Quem fala na mídia sobre o álcool e as outras drogas}

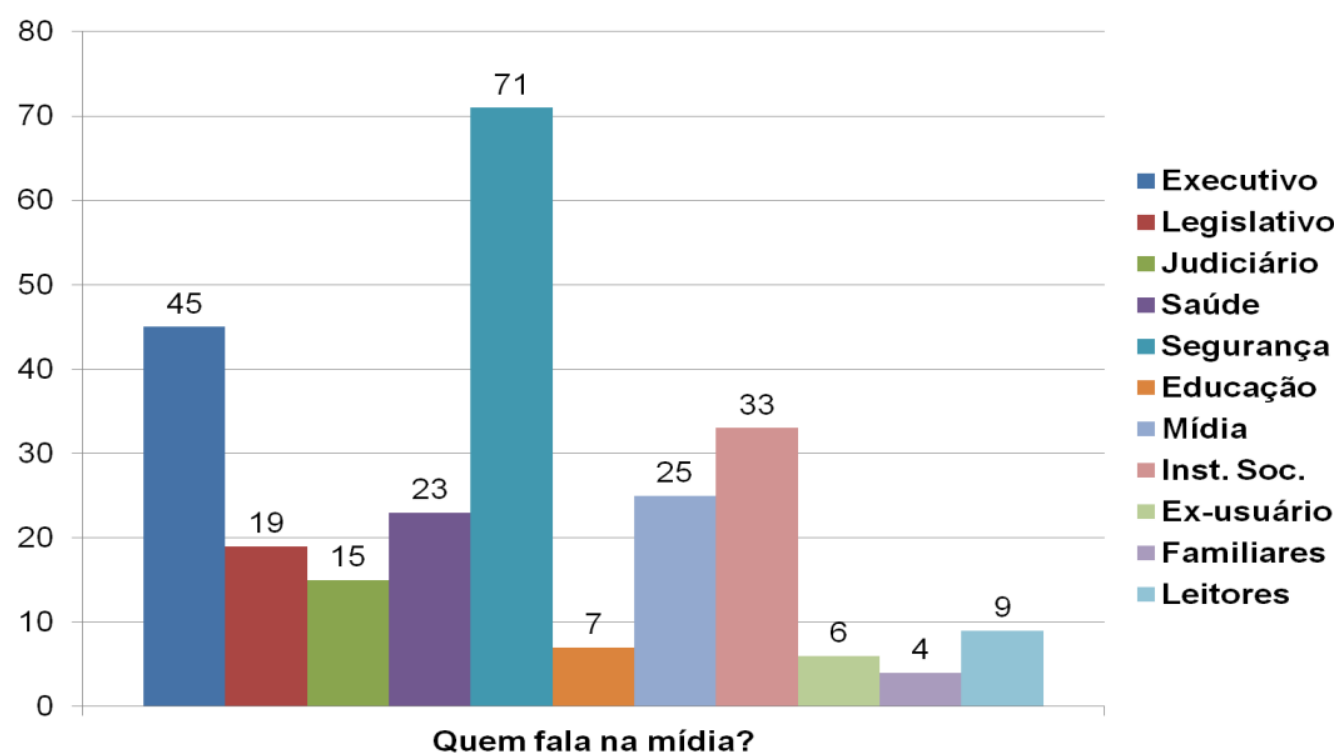

Fonte: Setor de Comunicação do CRP-07.

Através da análise do gráfico elegeu-se 7 (sete) principais grupos produtores dos discursos sobre o álcool e as outras drogas nas mídias em questão:

1. Os especialistas: predominam nas mídias analisadas a participação de profissionais da área da segurança, saúde, economia e educação na construção dos discursos sobre a temática. Dessa forma, vemos a utilização dos chamados "especialistas" como aqueles que dão legitimidade aos fatos apresentados como se esses fossem capazes de dizer "as verdades" sobre os assuntos em pauta. Destaca-se a ênfase que se dá aos discursos da área da segurança para o tratamento da temática da droga, direcionando o modo como serão produzidas as intervenções e práticas sociais dentro de lógicas punitivas e criminalizadoras.

2. Poder público: representando as instâncias do Executivo, Legislativo ou Judiciário eles aparecem nos meios de comunicação como aqueles que deveriam oferecer "respostas" a situação que está posta. Além disso, essas instituições viriam a ser referência de manejo a problemática social que é criada em torno do uso de drogas.

3. Sociedade Civil Organizada: nessa categoria encontramos falas de representantes de instituições da sociedade civil organizada como, por exemplo, Fundações e Institutos, que são selecionadas pelos meios de comunicação de acordo com o enfoque do que se quer colocar em discussão na matéria.

4. Cartas e opiniões de leitores: esse grupo se destaca por terem suas opiniões expostas através de recortes de fala que evidenciam discursos "a favor" ou "contra" determinada medida ou proposta. Diversos posicionamentos de leitores são recebidos pelos meios de comunicação. Dentre esses, os jornais impressos expõem aqueles comentários que vão ao encontro do que se deseja visibilizar. 
5. Mídia: visibilizada nos editoriais ou em matérias escritas pela equipe da própria meio de comunicação, essas notícias são dirigidas a sociedade na busca por mobilizá-la. O uso de drogas é colocado como uma "epidemia" que viria atingir todas as classes sociais. As substâncias são descritas como "drogas malditas" e "tentações sedutoras" que provocariam "efeitos destruidores" nos usuários e nos meios em que ele habita.

6. Familiares: frequentemente vinculados a um usuário, as reportagens que apresentam discursos advindos das famílias relatam experiências de parentes que vivenciaram algum contexto em que o uso de droga foi identificado. De caráter dramático, os relatos visam comover o leitor sobre o potencial "destrutivo e avassalador" do uso de drogas trazendo elementos discursivos que culpabilizam a substância química como possível desconstituidora de famílias. Os depoimentos descrevem as substâncias como elementos incompatíveis a relações sociais saudáveis.

7. Usuários abstinentes: os usuários têm espaços de fala quando se encontram em posição de abstinência. Dessa forma, suas falas são legitimadas quando essas se direcionam para perspectivas que os posicionam como sujeitos culpados e arrependidos de terem feito uso de substâncias. Além disso, as mídias inserem seus depoimentos construindo uma ideia do uso de drogas como um comportamento de caráter imoral, proibido e improdutivo. A abstinência é colocada como via de produção para uma "nova vida".

\subsubsection{Campos de Saber}

No quarto ponto de discussão foram elencados os campos de conhecimento que se colocam a serviço da construção dos discursos sobre a temática das substâncias químicas. Entende-se, que é através da produção de saberes que se constituem os fundamentos que serão utilizados como orientadores das ações sobre os usuários de drogas. Assim, as afirmações colocadas pelos profissionais de diversas áreas nos veículos de comunicação são os elementos que sustentam e qualificam os fatos afirmados nas reportagens. É importante destacar que a qualificação pode ser direcionada tanto para legitimar uma opinião como verdadeira, quanto para desqualificar determinados sujeitos ou falas. Através do gráfico abaixo (Figura 9), é possível visualizar as áreas de saber que mais estão presentes nas mídias analisadas. 


\section{Figura 9 - Campos de saber presentes nos discursos das mídias}

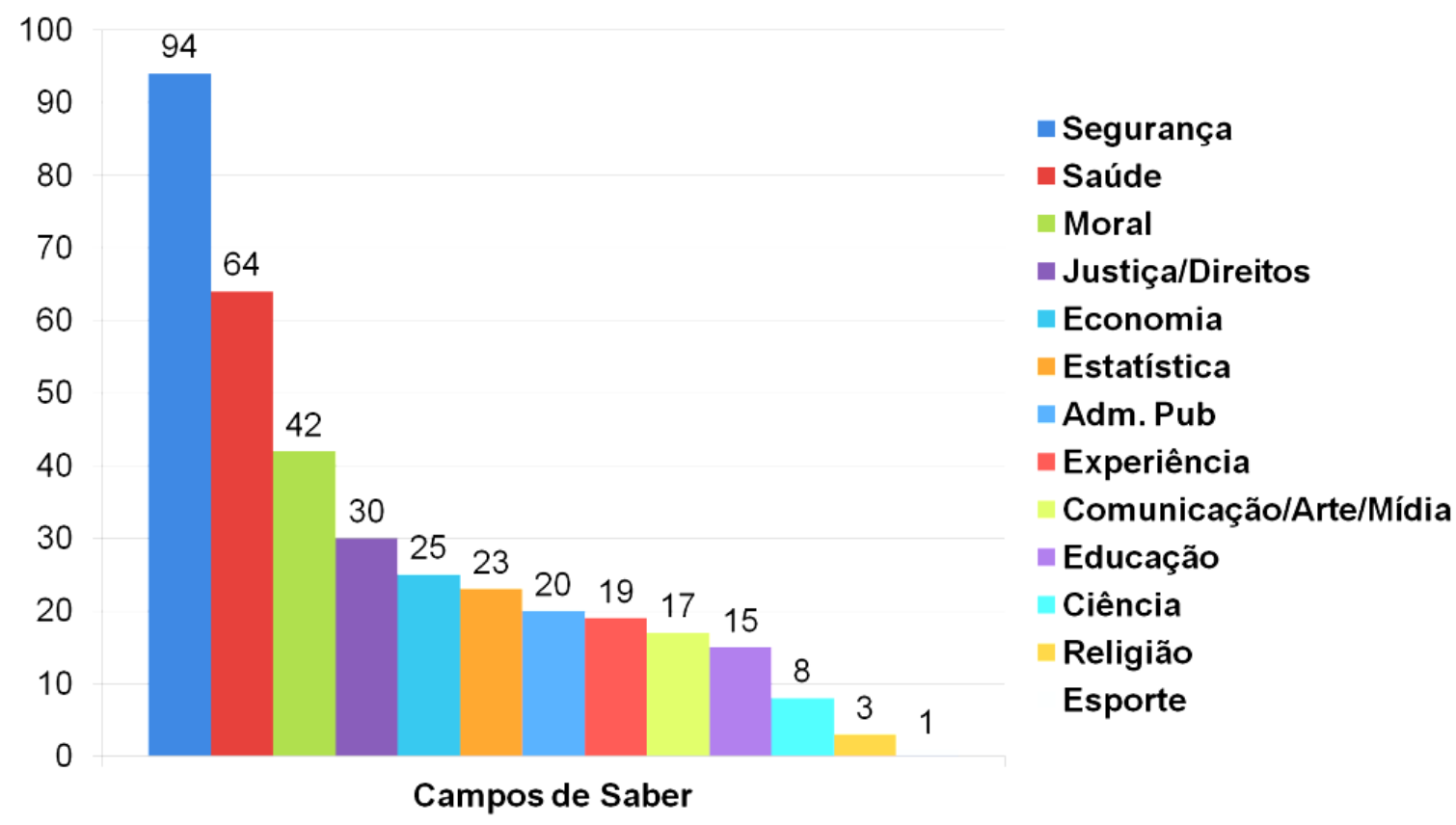

Fonte: Setor de Comunicação do CRP-07.

Como é possível visualizar no gráfico da Figura 9 foram elencadas 6 (seis) principais áreas de saber nas reportagens sobre o álcool e as outras drogas:

1. Segurança pública: apresenta-se nas reportagens, principalmente pelo fato de que o uso de drogas é criminalizado no Brasil. Dessa forma, a temática da droga é diretamente vinculada à área de saber da Segurança Pública; na qual os representantes dessa categoria expõem discursos que descrevem o contexto do uso de substâncias químicas como algo ilegal, passível de punição e imerso em contextos de criminalidade. Os usuários de drogas são frequentemente descritos com sujeitos potencialmente perigosos e, por isso, suspeitos que necessitariam ser vigiados, repreendidos e punidos.

2. Saúde: representado pelos profissionais dos serviços, a área da saúde se coloca para informar a sociedade sobre as ações de governo, possibilidades de atendimento e esclarecimento sobre procedimentos dos serviços que acolhem usuários de drogas. As substâncias são descritas como causadoras de dependência física e, por isso, os usuários necessitariam de internação e outras medidas de desintoxicação para que deixem de consumilas. Como solução, frequentemente se sugere parcerias entre órgãos públicos e serviços privados.

3. Moral: são reportagens desenvolvidas a partir de uma moralidade que envolve definições de valores, normas e noções do que seria certo ou errado, justo ou injusto, bom ou ruim dentro da temática das drogas. O uso dessas substâncias é descrito como uma ameaça à 
formação do "cidadão decente" e produtora de uma "decadência enquanto ser humano". Os discursos fundamentados nessa área do saber envolvem elementos que estabelecem padrões de higiene, de comportamento e do que seria esperado de um sujeito dentro de uma noção de normal e anormal. Frequentemente, incluem-se discursos embasados por preceitos religiosos.

4. Educação: apontam que o uso de drogas ocorre devido à "falta de sentido à vida" ocasionada, principalmente, entre os jovens. Assim, a educação e seus serviços como a escola, por exemplo, são colocadas como alternativas que viriam solucionar a problemática das drogas. O raciocínio dessas reportagens aponta que o usuário deve ocupar seu tempo e "mente" com atividades produtivas, de preferência profissionalizantes, capazes de gerar emprego e renda, sendo a educação uma das sugestões para essa inserção. Em determinadas reportagens a escola e suas "falhas" são apontadas como possíveis facilitadoras do uso de drogas, pois são contextos que não são atrativos aos jovens e, por isso, buscariam a substância para obter outros modos de prazer.

5. Economia: a questão econômica aparece, principalmente, nas reportagens sobre as campanhas de combate ao uso de drogas ou ações do governo vinculadas aos valores estimados gerados pelas vendas e consumo de drogas. Também se coloca em pauta os valores investidos na área da saúde nesse campo, assim como os gastos públicos obtidos pelas consequências do uso de substâncias. O álcool é colocado como a substância que mais ocasionaria gastos de saúde pública devido aos acidentes de trânsito que gera.

6. Estatística: a estatística aparece nas reportagens, de forma geral, diretamente vinculada a algum raciocínio ou ideia que se quer afirmar tendo os números como garantia de legitimidade. As matérias apontam números relacionados aos tipos de drogas consumidas, aos grupos que consomem, os locais onde é feito o consumo, os serviços disponíveis, números de internações ocorridas, os percentuais gastos públicos com serviços na área do uso de drogas, entre outros. 


\subsubsection{Soluções apontadas: repressão e higienismo}

Figura 10 - Soluções apontadas para a problemática do uso de drogas

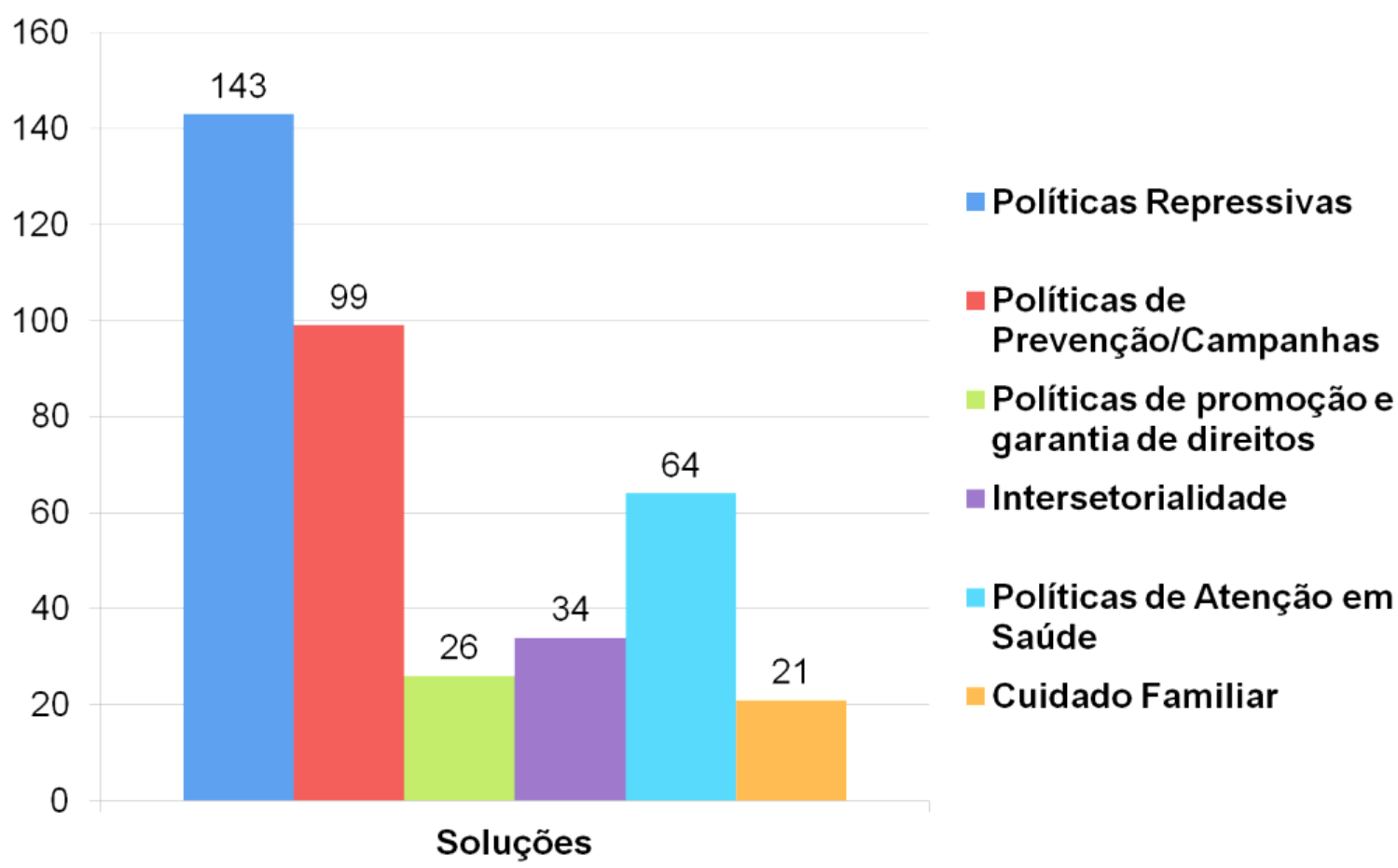

Fonte: Setor de Comunicação do CRP-07.

intervenção social no contexto do uso de drogas nas mídias analisadas:

1. Políticas repressivas: embasadas pelo discurso do risco e da periculosidade são propostas e indicadas práticas de intervenção pautadas na criminalização dos usuários, punição dos supostos "responsáveis" pela existência das drogas e encarceramento e internação daqueles que fazem o uso de substâncias químicas. Além disso, são colocadas em questionamento as atuais leis que comportam o uso e comércio de substâncias colocando ao leitor a ideia de que essas seriam "muito flexíveis" e deveriam ser mais "rígidas". As campanhas nessa categoria são pautadas pela catastrofização do uso de drogas em que se produz um discurso do medo. Aponta-se a droga como via de auto-destruição, solidão e morte acreditando que por essa ação os sujeitos evitarão consumir substâncias químicas. Os movimentos e políticas atuais de cuidado aos usuários de drogas como, por exemplo, o Movimento da Reforma Psiquiátrica e a Política de Redução de Danos, são negligenciados nos discursos postos nessa categoria.

2. Políticas de Prevenção/Campanhas: apostam na possibilidade de que o uso de álcool e outras drogas seja evitado/reduzido através de campanhas educativas baseadas na lógica da prevenção. No caso do álcool, são produzidos discursos que toleram seu uso desde que ele seja "moderado" e "adequado de acordo com a situação e a idade do usuário". Em relação às 
outras drogas, predominam discursos pautados pela busca da abstinência e com o objetivo final de extinção do uso de substâncias pela população.

3. Políticas de atenção em saúde: pouco pautadas, as Políticas de Atenção a Saúde dentro da perspectiva do Sistema Único de Saúde são alvo de críticas nas reportagens, principalmente, para que se apontem as "falhas" e a "ineficácia" do sistema atual de saúde no que se refere ao cuidado de usuários de drogas. Os Centros de Atenção Psicossocial para Usuários de Drogas (CAPSad) são pouco referidos. As sugestões que se mostram como aquelas que podem solucionar o problema, destinam-se a construção da ideia de que a reposta aos entraves nos atendimentos em saúde seria o aumento no número de serviços de internação.

\section{Psicologia e mídia: um diálogo necessário}

O presente artigo parte de uma proposta local que visava realizar uma análise das publicações veiculadas na mídia gaúcha sobre a temática de álcool e outras drogas. O objetivo foi trazer à Psicologia, e aos demais atores envolvidos na formulação e execução de políticas públicas, a possibilidade de se lançar em uma reflexão sobre o que vem sendo veiculado pela mídia sobre álcool e outras drogas e os efeitos dessas publicações para a construção de políticas públicas. Para isso, partimos da perspectiva de afirmação dos princípios da Reforma Psiquiátrica e da necessidade de construção de modelos de tratamento em saúde mental pautados pela garantia de direitos dos portadores de sofrimento psíquico, incluindo aqui os usuários de drogas.

Das 270 publicações analisadas, foi possível evidenciar que a hierarquização de temas, que Coimbra (2001a) aponta como uma das funções da mídia colocaram a temática do álcool e outras drogas como foco de notícia no ano de 2009. Assim, esse tema foi algo a ser noticiado cotidianamente, tendo visibilidade em notas, colunas de especialistas e formadores de opinião das mais diversas áreas. O tema passou a ser falado relacionado a uma diversidade de questões, mas, ainda, há um investimento significativo referente ao discurso da droga vinculado às práticas policiais, que enfatizam a relação das drogas com a criminalidade e as ações de repressão. Fica evidente que isso se refere ao reflexo de um contexto brasileiro no qual o uso de substâncias químicas ainda é uma ação criminalizada, com exceção do consumo de álcool, tabaco e medicações sob vigilância da ANVISA (Agência Nacional de Vigilância Sanitária).

As reportagens vinculadas à temática das drogas foram encontradas em pontos específicos do jornal, dando ao assunto caráter de destaque. Há um foco de investimento nos discursos sobre o usuário de drogas e as consequências do uso. Encontra-se uma ausência de reportagens sobre álcool e outras drogas nas sessões relacionadas à saúde, reforçando a forma 
como esse tema se torna notícia, sempre vinculado às questões relacionadas à violência e à criminalidade. Nesse contexto, percebe-se que a maioria das publicações não possui autoria. A ausência de uma autoria vincula-se a idéia de que a imprensa apresenta fatos, desta forma não é como se independente de quem redige a notícia ela será a mesma, posto que supostamente retrate a realidade. Entretanto, entende-se aqui que um mesmo assunto pode ser escrito de diferentes formas de acordo com os lugares de fala de quem os escreve, da perspectiva política do veículo de comunicação e dos jogos de interesses nos quais está inserido.

Nessa perspectiva, compreende-se a escrita como uma prática de veiculação de discursos e produção de sentidos os quais vão resultar em propostas sobre os modos como nos relacionamos com o mundo e conosco (FISCHER, 2002). Njaine; Minayo (2004), ao realizarem uma revisão da literatura científica nacional e internacional sobre violência nos discursos das mídias, identificaram os veículos de comunicação como responsáveis por construir sentidos aos elementos sobre os quais discorrem. Esses sentidos são pautados por valores específicos que direcionam o modo como as temáticas são abordadas. As imagens estereotipadas de determinados grupos que são divulgadas nas reportagens foram identificadas pelas autoras como formas de violência pouco reconhecidas pela sociedade e não colocadas em pauta de estudo pelos espaços acadêmicos.

Assim, coloca-se em evidencia nessa discussão o modo como os discursos sobre o álcool e as outras drogas são construídos a partir de imagens estereotipadas nas mídias analisadas, produzindo a ideia de que as drogas são seres animados, capazes de controlar os sujeitos e suas ações, tornando-os vulneráveis e perigosos. É interessante essa contradição posta, em que o usuário de drogas é descrito como alguém que ao mesmo tempo em que estaria se destruindo, perdendo suas capacidades e sua vida, mas também se tornaria um sujeito empoderado e violento. A caracterização do usuário de forma desumanizada e perigosa é o que possibilita colocar esse sujeito em um "estado de exceção" (AGAMBEN, 2009), abrindo espaço para que uma série de práticas de extermínio e exclusão se inscreva sobre eles.

Nas reportagens analisadas percebe-se a criação de um contexto de uso de drogas vinculado a existência de um estado de caos. Nesses contextos é que são chamados os "especialistas", aqui representados como todas aquelas áreas do conhecimento que supostamente teriam ou deveriam ter algo a dizer sobre o uso de drogas, para que estes ofereçam uma análise das situações de forma legitimada pelo próprio status que possuem e, assim, possam propor formas de manejo. Nas reportagens, foram encontradas falas diretamente atreladas aos cargos que esses ocupam. Alguns jornais deram mais destaque para os agentes da segurança pública e instituições policiais e outros colocam gestores e representantes do legislativo para produzir discursos sobre o tema. Para Ribeiro; Pergher; 
Torossian (1998) o uso de títulos profissionais ou de discursos vinculados a instituições que possuem reconhecimento social é utilizado pela mídia como uma ferramenta para firmar uma base sólida para a informação que está sendo transmitida. Nesse sentido, entendemos que o uso de profissionais na formulação de reportagens funciona como uma estratégia argumentativa para dar veracidade ao que está sendo escrito e as ações que são propostas.

A mídia, enquanto um ator importante na veiculação e produção de verdades sobre as drogas pode produzir efeitos significativos nas disputas em torno da construção de políticas sobre drogas. Nesse sentido, é fundamental que possamos colocar essas verdades em análise. O Sistema Conselhos de Psicologia tem produzido um debate que convoca a categoria profissional a estar atenta a essas configurações, para não tomar esses arranjos como naturais. Nesse sentido, afirma-se a importância da implicação da categoria com a garantia das políticas de saúde mental, das políticas para álcool e outras drogas e com o Programa de Redução de Danos preconizados pelo Ministério da Saúde, opondo-se aos movimentos contra-reforma que multiplicam práticas de higienismo e exclusão sobre usuários de drogas. 


\section{REFERÊNCIAS}

AGAMBEN, Giorgio. Estado de Excessão. São Paulo: Boitempo, 2007.

BRASIL. Ministério da Saúde. A Política do Ministério da Saúde para a atenção integral a usuários de álcool e outras drogas. Brasília: DF, 2003. 60 p.(Série B. textos básico de saúde).

BRASIL. Ministério da Saúde. Portaria n ${ }^{\circ}$ 1.059/GM de 4 de julho de 2005. Diário Oficial da União, Brasília, 4 de julho de 2005. s/p.

COIMBRA, Cecília. Mídia e Produção de Modos de Existência. Psicologia Teoria e Pesquisa. v. 1, n. 17, p. 001-004. jan./abr. 2001a.

COIMBRA, Cecília. Operação Rio: o mito das classes perigosas um estudo sobre a violência urbana, a mídia impressa e os discursos de segurança pública. Niterói: Oficina do Autor, 2001b.

FISCHER, Rosa Maria Bueno. O dispositivo pedagógico da mídia: modos de educar na (e pela) TV. Revista Educação e Pesquisa, São Paulo, v. 1, n. 28, p. 151-162, jan./jun. 2002. Disponível em: <http://dx.doi. org/10.1590/S1517-970220020 00100011> Acesso: em 02 jan. 2018.

FOUCAULT, Michel. História da Sexualidade II: O uso dos prazeres. 13. ed. Rio de Janeiro: Edições Graal. 2009.

NJAINE, Kathie; MINAYO, Marilia Cecília de Souza. A violência na mídia como tema da área da saúde pública: revisão da literatura. Ciência \& saúde coletiva, Rio de Janeiro, v. 9, n. 1, 2004. Disponível em: <http://dx.doi.org/10.15 90/S14 13-81232004000100020> Acesso: em 02 jan. 2018.

REIS, Carolina dos. (Falência Familiar) + (Uso de Drogas) $=$ Risco e Periculosidade: a naturalização jurídica e psicológica de jovens com medida de internação compulsória. 2012. 132f. Dissertação (Mestrado em Psicologia Social e Institucional) - Universidade Federal do Rio Grande do Sul, Porto Alegre.

RIBEIRO, Tatiana Weiss; PERGHER, Nicolau Kuckartz; TOROSSIAN, Sandra Djambolakdjian. Drogas e adolescência: uma análise da ideologia presente na mídia escrita destinada ao grande público. Psicologia: Reflexão e Crítica, Porto Alegre, v. 11, n. 3, 1998. Disponível em: <http://dx. doi.org/10.1590/S0102-79721998000300003> Acesso: em 02 jan. 2018.

SANTOS, Loiva Maria de Boni Santos (Org.). Outras palavras sobre o cuidado de pessoas que usam drogas. Porto Alegre: Conselho Regional de Psicologia do Rio Grande do Sul, 2010.

TORRES, Samantha; ECKER, Daniel Dall'Igna. Capacitação de profissionais sob a perspectiva da redução de danos: drogas, vamos pensar!. Revista Eletrônica Científica da UERGS, [S.1.], v. 3, n. 1, p. 39-62, abr. 2017. ISSN 2448-0479. Disponível em: <http://revista.uergs.edu.br/index.php/revu ergs/article/view/494>. Acesso em: 21 mar. 2018. 